\title{
GOVERNO, AÇÃo, FABRICAÇÃo E TRABALHO no pensamento de Hannah ARENDt
}

\section{[GOVERNMENT, ACTION, WORK AND LABOR IN HANNAH ARENDT'S THOUght]}

Mariana de Mattos Rubiano

Pós-doutoranda em Filosofia na Universidade Federal de São Paulo Bolsista FAPESP

DOI: http://dx.doi.org/10.21680/1983-2109.2018v25n48ID14149

Natal, v. 25, n. 48

Set.-Dez. 2018, p. 109-128

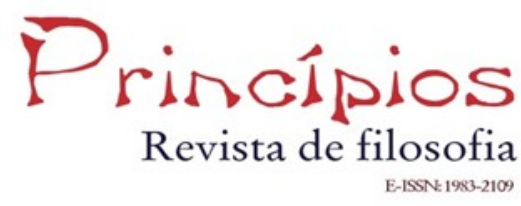


Resumo: Este artigo tem como objetivo examinar os conceitos de governo e dominação no pensamento de Hannah Arendt. A autora associa estes conceitos com a ação, a fabricação e o trabalho. Ainda, ela indica como os significados de governo e dominação mudam de acordo com a hierarquia das atividades humanas.

Palavras-chave: Governo; Dominação; Ação; Fabricação; Trabalho.

Abstract: This article aims at examining the concepts of government and rulership in Hannah Arendt's thought. The author connects these concepts with action, work and labor. Moreover, she indicates how the meanings of government and rulership change according with the hierarchy of the human activities.

Keywords: Government; Rulership; Action; Work; Labor. 
Em A Condição Humana, Hannah Arendt apresenta uma narrativa sobre a mudança da hierarquia das atividades humanas da Antiguidade para a Modernidade. A autora indica que as atividades humanas passaram a ser realizadas de modo distinto ao tratar da desvalorização da ação política e da valorização da fabricação - atividade que produz bens duráveis, artefatos que compõe o mundo humano - e do trabalho - atividade que garante a sobrevivência, a manutenção do corpo biológico. As mudanças nos espaços privado e público, a emergência da esfera social, o modo moderno de produzir conhecimento por meio de experiências e instrumentos, em especial a partir da invenção do telescópio, a tecnologia e as melhorias das ferramentas de trabalho, não afetaram apenas uma ou outra parte da vida humana, mas todas a atividades realizadas pelos homens.

Não é possível tratar neste artigo de toda esta narrativa da inversão da hierarquia das atividades humanas e de suas consequências, isto exigiria um fôlego e capacidade de síntese que escapa a este texto e a mim. Levando isso em conta, proponho neste artigo apresentar como a inversão na hierarquia das atividades humanas provocou mudança na concepção de governo. Com isso, além de apresentar uma narrativa sobre as transformações na concepção de governo da Antiguidade para a Modernidade, tentarei recolocar a questão que animou a escrita de $A$ Condição Humana, a saber, "o que estamos fazendo?" focando na questão do governo. Em outras palavras, buscarei apontar elementos no pensamento de Arendt que possam nos auxiliar a pensar qual tipo de concepção de governo estamos construindo e apoiando.

\section{Narrativa da concepção de governo}

Governo no pensamento da autora tem dois sentidos. Por um lado, governo (government) significa o poder organizado e institucionalizado. ${ }^{1}$ Poder, para Arendt, consiste em um potencial de

${ }^{1}$ V. Arendt, 2010b, p. 69 
realizar algo no mundo e a sua condição de existência é o espaço da aparência onde os homens possam se inter-relacionar por meio do discurso e da ação. Somente neste espaço é possível formular um princípio de ação compartilhado por meio da troca de opiniões e de diferentes perspectivas, somente neste espaço os agentes podem se associar para mudar o mundo e para iniciar algo novo. No espaço da aparência o que é feito e dito se torna público, ou seja, visível e audível a todos. Uma ação quando é vista por todos pode ser apoiada: as pessoas podem agir para sustentá-la. O governo institucionaliza e organiza o poder para preservá-lo, para que os laços públicos entre os seres humanos sejam duráveis e para que a atividade política seja possível e ordinária. ${ }^{2}$ Nesse sentido, o governo tem como sentido preservar a atividade política.

Por outro lado, governo significa dominação (rulership). Neste sentido, governo exige a divisão entre governantes e governados, entre os que ordenam a vida em comunidade e, por isso, mandam e aqueles que simplesmente executam as ordens e não participam das decisões acerca dos assuntos comuns. Segundo Arendt, quando o governo é entendido como dominação, a ação é desvalorizada em favor de outras atividades humanas e, assim, o governo passa ater um objetivo externo à política. Em outras palavras, a política é vista como um meio para atingir uma finalidade.

Para a autora, em alguns raros momentos a ação foi considerada a atividade humana mais elevada, como na polis grega, na república romana e nas revoluções. Nestes momentos a finalidade, ou melhor, o sentido da política foi a liberdade. ${ }^{3}$ Isto é, a razão de

\footnotetext{
${ }^{2}$ Cf. Arendt, 2010a, p. 250.

3 “'A polis grega foi outrora a 'forma de governo' que proporcionou aos homens um espaço para o aparecimento onde pudessem agir - uma espécie de anfiteatro onde a liberdade podia aparecer" (Arendt, 2005, p. 201). "A liberdade romana era um legado transmitido pelos fundadores de Roma ao povo romano; sua liberdade ligava-se ao início que seus antepassados haviam estabelecido ao fundar a cidade [...]" (Arendt, 2005, p. 215). Nesta passagem Arendt liga liberdade e fundação em dois aspectos, a liberdade se torna possível com a abertura do espaço público-político e com a emulação dos grandes feitos dos
} 
ser da política consistia em que os homens pudessem adentrar num espaço onde uma igualdade era estabelecida - ali ninguém dominava ou era dominado e ninguém estava sob o jugo das necessidades da vida. Neste espaço, cada um podia tomar parte nos assuntos comuns, constituir um mundo próprio e compartilhado entre pares. Nessa perspectiva, era preciso criar e manter espaços e instituições onde os homens pudessem agir e falar uns com os outros, onde pudessem aparecer publicamente para debater, deliberar e agir em conjunto. ${ }^{4}$ Dito de forma mais simples, uma vez que na Grécia antiga, na república romana e nas revoluções os homens visavam à liberdade pública, eles se ocuparam em constituir e preservar uma forma de governo em que a ação livre fosse possível.

No entanto, Arendt aponta que, tanto no campo teórico como no prático, surgiram outras concepções que buscavam formular ou sustentar formas de governo que não têm como objetivo a ação livre. Para a autora, esta tentativa de evitar a ação se deu em razão de suas características. Por envolver um pluralidade de agentes livres, a ação é imprevisível: não é possível saber com certeza o rumo que a cadeia de atos e iniciativas dos agentes vai tomar, quando a ação terá um término - pois o que foi iniciado pode ser continuado e apropriado de diferentes formas por meio da reação

antepassados, ao tomar os fundadores como exemplos, os romanos se engajavam na ação. A liberdade também é relacionada à constituição do espaço político nas Revoluções Americana e Francesa: "Para os homens do século XVIII, porém, ainda era evidente que precisavam de uma Constituição para estabelecer os limites da nova esfera política e definir as regras em seu interior, e que deviam fundar e constituir um novo espaço político onde a 'paixão pela liberdade pública' ou a 'busca da felicidade pública' pudessem ser exercidas pelas gerações futuras, de forma que o espírito 'revolucionário' sobreviveria ao fim efetivo da revolução" (Arendt, 2011, p. 171).

${ }^{4}$ Arendt afirma a íntima relação entre liberdade e política em diversos pontos de sua obra (v. p. ex. Arendt 2005, p. 192/197; 2011, p. 58/278. Da mesma forma, a autora reiteradamente aponta que é preciso um espaço publicamente organizado para que a liberdade possa ser experimentada de modo duradouro. Cf. Arendt, 2005, p. 194; 2011, p. 59. 
do público -, nem quantas pessoas estão envolvidas neste empreendimento comum. Levando isso em conta, evitar a ação visa a evitar a imprevisibilidade do mundo humano; a irreversibilidade dos atos, e o anonimato dos agentes.

De acordo com Arendt, para Platão a atividade mais valorizada era a contemplação e, nessa medida, a finalidade da política deveria ser a garantia do modo de vida do filósofo. ${ }^{5}$ Para tanto, seria necessário governar de acordo com a verdade e seguindo os preceitos da razão. A defesa do rei-filósofo de Platão é mais do que a recomendação de que um governante seja sábio e governe de acordo com as ideias claras e distintas, indica também uma forma de governo baseada na fabricação em que o governante impõe os certos padrões aos assuntos comuns. Nesse sentido, Platão formulou um tipo de governo que não era pautado na ação livre.

"Na República, o rei-filósofo, aplica as ideias como o artesão aplica suas regras e padrões; 'faz' sua cidade como o escultor faz uma estátua [...]" (Arendt, 2010a, p. 283). Arendt aponta que o principal termo da filosofia platônica, a ideia, vem da fabricação, pois a imagem ou a forma [eidos] do produto que será fabricado determina todo o processo de produção, os meios, instrumentos e modo de execução. Para que a contemplação impere sobre a ação, prescreva regras a serem seguidas na vida política, é preciso que o governante seja o senhor de todo empreendimento iniciado no espaço público, os demais não podem ter qualquer iniciativa que mude ou adicione algo ao empreendimento. ${ }^{6}$

\footnotetext{
${ }^{5}$ A teoria de Platão, na interpretação da autora, foi marcada pelo conflito entre a polis e a filosofia, principalmente pela morte de Sócrates, que pareceu ter comprovado que a vida dos filósofos não estaria segura enquanto o debate público guiasse a vida em comum na cidade. A partir de então, Platão teria desvalorizado a persuasão em favor do governo do filósofo. "Politicamente, a filosofia de Platão mostra a rebelião do filósofo contra a polis. O filósofo anuncia sua pretensão de governar, mas não tanto por amor à polis e à política [...], como por amor à filosofia e à segurança do filósofo" (Arendt, 2005, p. 146).

${ }^{6}$ V. Arendt, 2005, p. 154 e 155.
} 
Segundo Arendt, em As Leis, Platão afirma que o início [arché] determina o governo [archein]. Para o autor, o governo não engendraria um ato inicial que é levado adiante por meio da iniciativa livre de outros agentes e, por isso, ele não trata da criação e preservação de espaços destinados ao debate e à persuasão. ${ }^{7}$ Conforme a autora, uma vez que Platão considera que o governo deve consistir na execução de um plano definido pelo rei-filósofo, ele se ocupa em legitimar a dominação do governante sobre os governados. ${ }^{8}$

Apesar desta concepção platônica de governo ter perpassado toda a tradição, ela não chegou a desempenhar um papel perceptível na história até a Modernidade. Somente aí, a identificação entre governar e fabricar teve implicações práticas relevantes. Com a ascensão da mentalidade do homo faber, isto é, da convicção de que a atividade mais importante realizada pelo homem é a fabricação e com o desenvolvimento dos meios de coerção e violência, foi possível governar nos moldes do fazer. ${ }^{9}$

\footnotetext{
${ }^{7}$ Arendt divide a ação em dois momentos o início e seu desenrolar. Tal divisão é baseada nos dois verbos que designavam a ação nas línguas grega antiga e latim: "[...] ambas as línguas possuíam dois verbos para designar aquilo que chamamos uniformemente de agir. As duas palavras gregas são árkhein: começar, conduzir e, por último, governar, e práttein: levar a cabo alguma coisa. Os verbos latinos correspondentes são agere: pôr alguma coisa em movimento, e gerere, que é de árdua tradução e que de certo modo exprime a continuação permanente e sustentadora de atos passados cujos resultados são as res gestae, os atos e eventos que chamamos de históricos" (Arendt, 2005, p. 214).

${ }^{8}$ Cf. 2010a, p. 278. Conforme Arendt, estas concepções de Platão contaminaram toda a tradição do pensamento político. E no decorrer do tempo, de alguma forma, a noção de iniciar desapareceu do conceito de governo e, assim, governar se tornou sinônimo de dominar. Conforme Arendt, Aristóteles, por exemplo, procura estabelecer uma legitimidade para explicar divisão entre governantes [rulers] e governados [ruled] e define o governo como dominação [rule]. Cf. Arendt, 2002, p. 275.

${ }^{9}$ Sobre a promoção da fabricação e a emergência da mentalidade do homo faber, v. Arendt (2010a, p. 368-381).
} 
No momento em que a mentalidade do homo faber foi valorizada, os homens modernos puderam recorrer à filosofia política para buscar formas de suplantar a ação. De acordo com Arendt, a substituição da ação pela fabricação implica em instrumentalizar a política. A produção de uma coisa deve ser sempre útil, o produto serve para algum fim, nesta perspectiva, o governo também deve ter uma finalidade.

A substituição da ação pela fabricação e a concomitante degradação da política em um meio para atingir um fim supostamente "superior' - na Antiguidade, a proteção dos bons contra o domínio dos maus, em geral, e a segurança dos filósofos em particular; na Idade Média, a salvação das almas; e, na era moderna, a produtividade e o progresso da sociedade são tão antigas quanto a tradição da filosofia política. (Arendt, 2010a, p. 286)

Na perspectiva da autora, os objetivos que o governo deve atingir também possuem uma história: para Platão, o governo deveria garantir o bem comum e a segurança de quem se dedicava à contemplação; para a filosofia cristã, o objetivo passou a ser uma certa ordem na esfera secular para que fosse possível a dedicação à vida interior e à salvação; na Modernidade, por sua vez, a valorização do homo faber e do animal laborans fez com que o governo se preocupasse, primeiramente, com a produção de uma certa sociedade e, depois, com o processo vital, isto é com a reprodução e manutenção da sociedade. ${ }^{10}$

A autora depois de indicar a ascensão do homo faber e a glorificação da atividade de fabricar na Modernidade, mostra que a mentalidade do fabricante foi suplantada pela mentalidade do animal laborans, isto é, pela concepção de que o trabalho - a pro-

\footnotetext{
${ }^{10}$ Vale sublinhar, que embora o conceito de governo, desde sua origem, tenha trazido sérios empecilhos para a atividade política, não conseguiu eliminar a ação livre por completo.
} 
dução e o consumo que garantem a sobrevivência dos corpos consiste na principal atividade humana. ${ }^{11}$

Nesse contexto, o trabalho passou a ser a atividade humana mais importante e as coisas que não eram necessárias para manter o processo vital tornaram-se secundárias ou supérfluas. Com isso, os assuntos comuns foram invadidos por questões econômicas e sociais na medida em que o governo passou a ser relacionado com o estímulo da produtividade do trabalho e com medidas sociais para garantir a sobrevivência. ${ }^{12}$

Arendt critica as formas de fabricação e de administração que visam a substituir a ação, a restringir ou impedir a atividade política. De acordo com ela, quando a política é instrumentalizada, entendida como meio para atingir um objetivo extra-político, as instituições públicas deixam de abrigar o debate ampliado e a ação em conjunto para dar espaço à execução de planos do governante e à administração da sociedade. Ao considerar o pensamento da autora é possível notar que existe uma imbricação entre a hierarquia das atividades humanas, o lugar onde elas são realizadas e modo de realização, a concepção de finalidade da política e a forma de governo defendida.

Em A Condição Humana, Arendt defende que a promoção da fabricação - atividade responsável por produzir bens duráveis - e

\footnotetext{
${ }^{11}$ De maneira resumida, em A Condição Humana, argumenta-se que, na Antiguidade, o mundo - criado e preservado por meio de atos, discursos e de artefatos culturais - consistia a principal preocupação dos homens. Ele deveria ser preservado para que as coisas e feitos humanos perdurassem no tempo, e remediasse a mortalidade dos homens. Com o surgimento do cristianismo, a alma de cada homem foi dotada de imortalidade. Assim, a vida individual foi considerada sagrada e as faculdades interiores, como querer e pensar, foram valorizadas em detrimento das atividades mundanas. Com a secularização, a vida individual volta a ser considerada mortal, como fora na Antiguidade. No entanto, a imortalidade passa a ser entendida como atributo da espécie humana. A vida biológica se torna, então, um bem supremo. Cf. Arendt, 2010a, p. 384/389/400-406.

${ }^{12}$ V. Arendt, 2010a, p. 393.
} 
do trabalho - atividade ligada à natureza, à produção e ao consumo - e a emergência da mentalidade do homo faber e do animal laborans, trouxeram entraves para a ação política. Governar, nesse contexto, tornou-se sinônimo de fabricar e administrar uma sociedade.

Essa mudança nos assuntos comuns também é discutida por Arendt em sua narrativa da Revolução Francesa. Este evento contou com três momentos distintos que indicam o aparecimento da ação, sua substituição pelo fazer para sanar a questão social e o fazer que promoveu a sociedade de classes e a produtividade. No início desta revolução, o gosto pela liberdade levou os homens ao espaço público, à ação em conjunto que derrubou a monarquia absolutista, seguida pelo debate acerca de como constituir novos direitos e um novo corpo político onde os cidadãos pudessem tomar parte nos assuntos da comunidade. Neste momento a ação foi considerada a principal atividade humana e as comunas, clubes e sociedades populares eram os espaços mais valorizados. Quando Robespierre se tornou chefe do governo revolucionário, a questão social, isto é, a resolução do problema da miséria, tornou-se a maior preocupação pública. Uma vez que a finalidade do governo passou a ser o fim da pobreza, o Comitê de Salvação Pública e a Assembleia Nacional se tornaram as instituições mais importantes, a noção de vontade geral e a concepção de fundação como fazer passaram a guiar o governo. ${ }^{13}$ Quando os pobres apareceram na cena pública, os franceses perceberam que a liberdade não era possível para aqueles que estavam submetidos à opressão da necessidade de seus corpos. A concepção de que toda a nação francesa possuía uma só vontade pareceu ser verdadeira em virtude da massa de miseráveis que clamavam por pão. ${ }^{14}$ Nesse

\footnotetext{
13 Arendt cita frases de Robespierre para indicar sua preocupação com a miséria: "Tudo que é necessário para manter a vida deve ser um bem comum [...]" (Arendt, 2011, p. 94) "A república? A monarquia? Conheço apenas a questão social" (idem, ibidem, p. 89).

${ }^{14}$ Cf. Arendt, 2011, p. 134.
} 
contexto, a noção de que o governo deve seguir a vontade geral e que sua finalidade seria resolver o problema da miséria foi adotada, assim, o debate público perdeu importância e parecia ser necessário apenas a execução de medidas de emergência para acabar com a pobreza. ${ }^{15}$ Além disso, uma vez que a vontade geral era considerada una e indivisível, as opiniões divergentes foram consideradas como expressões de interesses particulares e quem discordasse do governo revolucionário deveria ser perseguido como inimigo da nação. Por fim, a concepção de fundação como fazer prescreveu o uso de violência para atingir os fins desejados. ${ }^{16}$

De acordo com Arendt, Robespierre se apoiou no pensamento de Maquiavel na medida em que considerou que era preciso estar só para fundar ou reformar uma república e que, para esse fim supremo, todos os meios eram justificados. ${ }^{17}$

Um terceiro momento da Revolução Francesa também se relaciona à aplicação da fabricação ao governo. A ditadura de Napo-

${ }^{15}$ Sobre a associação entre pobreza e vontade geral, ver Arendt (2011, p. 112114).

${ }^{16}$ Arendt afirma que a violência, por vezes, é necessária na fabricação - pode ser preciso violar a natureza para produzir um objeto. Por exemplo, não é possível fazer uma mesa sem derrubar árvores. Nas cidades antigas, a violência era mantida fora do espaço público, ela deveria ser limitada para não colocar a liberdade dos cidadãos em risco. Já na modernidade, houve a glorificação da violência, como se ela fosse capaz de produzir algo novo no mundo. "Ao afirmar que 'a violência é a parteira de toda a velha sociedade grávida de uma nova sociedade', ou seja, de toda a mudança histórica e política, Marx apenas sintetiza a conviç̧ão dominante em toda a era moderna e extrai as consequências de sua crença mais íntima, a de que a história é 'produzida' pelo homem, tal como a natureza é 'produzida' por Deus" (Arendt, 2010a, p. 285).

${ }^{17}$ Nas palavras de Arendt (2005, p. 184): "Compreendiam o ato de fundar inteiramente à imagem do fazer; a questão para eles era, literalmente 'fazer' uma Itália unificada ou uma república francesa, e sua justificação da violência guiava-se pelo seguinte argumento [...]: não se pode fazer uma mesa sem abater árvores, nem fazer uma omeleta sem quebrar ovos; não é possível fazer uma república sem matar gente". 
leão visou a promover a economia e a sociedade de classes. ${ }^{18}$ Para a autora, esta revolução revelou "a mesma combinação do antigo entusiasmo romano pela fundação de um novo corpo político com a glorificação da violência como único meio de 'produzir' esse corpo" (Arendt, 2010a, p. 285).

É possível notar que Arendt em A Condição Humana trata de maneira mais abrangente e conceitual da noção de que o governo deve seguir os moldes da fabricação e aponta os eventos que valorizaram esta atividade na modernidade. Em Sobre a Revolução, ela mostra como a substituição da ação pela fabricação se deu em um evento específico. Além disso, a autora afirma que a Revolução Francesa ofereceu um modelo de intervenção para os intelectuais: a partir dela os teóricos do século XIX e XX puderam unir a atitude do filósofo desde Platão - a qual divide a comunidade entre os que sabem o que deve ser feito e os que não sabem e somente executam ordens - com o a ditadura de Robespierre e a de Napoleão. Assim surgiu a figura do revolucionário profissional, aquele que estuda as revoluções precedentes para formular um plano para fazer uma sociedade bem ordenada. ${ }^{19}$

Levando isso em consideração, pode-se notar que a substituição da ação pela fabricação no âmbito do governo foi acompanhada de um modelo teórico de intervenção dos intelectuais. Conforme foi dito anteriormente, para Arendt, na modernidade o governo foi relacionado não só com a fabricação, mas também com a administração. Quando o trabalho foi valorizado, as questões econômicas e sociais começaram a se tornar as principais preocupações públicas e, dessa forma, a administração gradativamente se tornou fundamental no governo. Nesse contexto, o liberalismo surgiu como a tradição de pensamento que promoveu a economia política como a ciência que deve guiar o governante e que define o governo como garantidor da independência individual e da segurança. A

${ }^{18}$ Cf. Arendt, 2011, p. 109.

${ }^{19}$ Cf. Arendt, 2011, p. 325-326. 
concepção de liberdade liberal indica isso. Ser livre na perspectiva do liberalismo consiste em ter liberdade de crença, de expressão, de ir e vir, de empreendimento, de negociação. É, portanto, algo que se refere ao espaço privado e ao indivíduo isolado, não ao espaço público, à participação e à comunidade política.

Na medida em que o trabalho é considerado como a principal atividade humana, a noção platônica de que o governo deve ser guiado pela verdade e pelo saber sobre a justiça, a coragem etc, dá lugar a concepção de que o governo agora deve ser conduzido de acordo com a racionalidade econômica. Em outras palavras, o modelo de governante deixa de ser o sábio para se tornar o especialista em economia e administração. Quando a preocupação central do governo se tornou a sobrevivência dos indivíduos e o processo vital, a medida pública mais importante passou a ser a organização da produção para que se tenha abundância.

O pensamento de Arendt também aponta que o governo, desde a Antiguidade, foi relacionado com a vida feliz. Embora a promoção da felicidade continue sendo associada ao governo, na Modernidade, a concepção de felicidade mudou e, consequentemente, as medidas que poderiam promovê-la. Para a autora, quando a vida se tornou o bem supremo, a felicidade passou a ser baseada na produtividade: tudo o que favorece o trabalho e alivia a dor e o esforço desta atividade. O cálculo do prazer e da dor de Bentham é, para a autora, o pensamento que representa a preocupação com a sobrevivência, o afastamento do espaço público para a dedicação exclusiva às atividades econômicas. Segundo Arendt (2010a, p. 386), o pressuposto básico de Bentham consiste em que "o que todos os homens possuem em comum não é o mundo, mas a uniformidade de sua própria natureza, o que se manifesta na uniformidade dos cálculos e na uniformidade com que todos são afetados pela dor e pelo prazer [...]".

A felicidade nesse sentido está imbricada com a segurança. Para alcançar a felicidade e a segurança, o governo deve liberar as pessoas das atividades públicas para que elas se ocupem com o 
prazer e a satisfação das necessidades biológicas por via do consumo. Para tanto, era preciso fomentar a produtividade do trabalho. De acordo com a autora, nos séculos XIX e XX o governo passou a ser considerado

[...] como o protetor nomeado não tanto da liberdade, como do processo vital, dos interesses da sociedade e dos indivíduos. A segurança continuava sendo o critério decisivo; não a segurança individual contra a "morte violenta", como em Hobbes (onde a condição de toda a liberdade é a liberação do medo), mas uma segurança que permitisse um desenvolvimento uniforme do processo vital da sociedade como um todo. (Arendt, 2005, p. 196)

Com a promoção da atividade do trabalho, a forma de governo defendida era a de uma autoridade limitada - para garantir a independência dos indivíduos no espaço privado - e a representação - para "liberar" a maioria dos cidadãos das atividades públicas e estimular as atividades econômicas. Nessa perspectiva, a única coisa que os seres humanos teriam em comum seriam os interesses privados, não existiria interesses ou princípios compartilhados e publicamente constituídos. Uma vez que o governo é nomeado para proteger a propriedade uns dos outros e permitir a luta competitiva por mais riqueza, ${ }^{20}$ ele não deveria resguardar espaços para o debate público. Ora, sem estes espaços, o interesse e os princípios compartilhados não podem ser constituídos. Para dizer de outro modo, esta concepção de governo ao evitar ação e o debate público e ao estimular as atividades privadas faz desaparecer o interesse comum e sustenta apenas os interesses privados.

A questão do governo representativo é discutido de modo mais detalhado na obra Sobre a Revolução. Lá a autora indica uma relação entre a preocupação pública com a questão social e econômica e a concepção de representação. O governo representativo é mais do que uma solução para governar grandes territórios com uma vasta população, trata-se de um modo eficiente de evitar a

${ }^{20}$ Cf. Arendt, 2010a, p. 84. 
ação e a formação de interesse e princípios comuns. A partir do momento em que emergiu na cena pública o problema da pobreza em massa na Revolução Francesa, os eleitos entenderam que deveriam representar a vontade geral da nação. ${ }^{21}$ Nesse contexto, o governo deveria tomar medidas para satisfazer as necessidades dos famintos, organizar a comunidade para evitar a escassez. Já na Revolução Norte-Americana, quando emergiu a preocupação com a economia e a abundância, os eleitos entenderam que deveriam representar os interesses dos eleitores. Os representantes, nesse sentido, não precisavam levar em conta a comunidade como um todo, mas deveriam governar de acordo com as orientações de lobbies e grupos de pressão. ${ }^{22}$

Ainda neste livro a autora aponta que a forma de governo representativo com o passar do tempo perdeu importância para a burocracia. Sobretudo no século $\mathrm{XX}$, as instâncias técnicas do Estado foram valorizadas.

[...] todas as questões políticas no Estado de bem-estar social são, em última análise, problemas administrativos, a ser tratados e decididos por especialistas, caso em que nem mesmo os representantes do povo chegam a dispor de uma autêntica área de ação [...]. (Arendt, 2011, p. 340)

Para Arendt, quando se tornou central a noção de que o conhecimento e o fazer dos especialistas deveriam guiar o Estado e todas as questões públicas, a forma privilegiada de governo passou a se basear na administração burocrática. Nas palavras da autora: "o governo, no sentido antigo, deu lugar, em muitos aspectos, à administração" (Arendt, 2005, p. 47). Com isso, surgiram outras dificuldades para a ação e para a liberdade pública. O governo nos moldes da fabricação oblitera a ação em razão da centralização das decisões, do uso da violência para que os cidadãos cumpram or-

\footnotetext{
${ }^{21}$ V. Arendt, 2011, p. 205.

${ }^{22}$ Cf. Arendt, 2011, p. 300.
} 
dens e levem a cabo a ideia de sociedade formulada pelo governante. Por sua vez, com a emergência da burocracia, especialistas passaram a calcular o interesse da sociedade e indicar as regras que promoveriam o bem-estar, estas devem nortear o funcionamento do Estado e o comportamento das pessoas. ${ }^{23}$

Ao invés de ação, a sociedade espera de cada um dos seus membros certo tipo de comportamento, impondo inúmeras regras, todas elas tendentes a "normalizar" os seus membros, a fazê-los comportarem-se, a excluir a ação espontânea ou a façanha extraordinária. (Arendt, 2010a, p. 49)

Ao primeiro olhar, o governo burocrático parece ser racional e não operar nenhuma opressão, mas ao impor normas aos cidadãos e regras de funcionamento ao Estado acaba por reduzir o espaço de debate e de ação livre e visa a estimular principalmente as atividades privadas.

Os defensores desse sistema, que atualmente é o sistema do estado de bem-estar social, precisam negar, se são liberais e possuem convicções democráticas, a própria existência da felicidade e da liberdade públicas; precisam insistir que a política é um fardo e que seu fim não é político em si. (Arendt, 2011, p. 337)

Levando o pensamento arendtiano em conta, podemos afirmar que a partir do século XIX a noção de governar passou a envolver tanto a fabricação quanto a administração. A preocupação com o social e o econômico engendrou duas concepções, a saber, a de fazer uma nova sociedade e a de gerenciar o trabalho e as coisas produzidas. Em outras palavras, teoricamente, governar se tornou, em um primeiro momento, executar um plano para mudar a sociedade de alto a baixo e, em um segundo, manter e reproduzir tal

${ }^{23}$ Como tudo está baseado em cálculos e regras das ciências econômicas e sociais, esta forma de governo não possui pessoalidade, ninguém se responsabiliza pelas decisões. Por isso Arendt diz que a burocracia é o governo de ninguém. V. Arendt, 2010a, p. 49. 
sociedade. O governo que tem como principal elemento a fabricação assume, preferencialmente, a forma da monarquia ou da ditadura: apenas um homem ou um pequeno grupo define o que deve ser feito e os outros executam ordens. Mas quando o trabalho foi considerado a atividade humana mais importante, a forma de governo mais adequada se tornou a burocracia, que é mais eficiente para administrar e fomentar as necessidades da vida à produtividade do trabalho.

A burocracia faz com que o Estado funcione de acordo com certas regras determinadas por um saber técnico e por especialistas. Assim, a autoridade da burocracia não é política uma vez que não pressupõe o reconhecimento das virtudes ou qualidades políticas dos especialistas. A autoridade da burocracia se parece com a autoridade dos cientistas que é definida pelos próprios cientistas por meio de certos critérios que envolvem a comprovação de hipóteses e excluem o debate e a persuasão em um espaço público. ${ }^{24}$ As regras burocráticas, nesse sentido, devem compelir a todos como se tratassem de verdades científicas.

Além de tratar da predominância da burocracia no governo, a autora indica os elementos que formaram o Estado de bem-estar social. Este tipo de Estado ao defender a democracia representativa e a preocupação com a economia e o social reduz o espaço público à disputa de forças e a negociação entre representantes de grupos de pressão. $O$ debate público se degenera em concorrência entre os interesses particulares para definir a forma de funcionamento do Estado, o uso do dinheiro público e o direcionamento do investimento ${ }^{25}$ e deixa a definição das políticas públicas a cargo dos quadros técnicos estatais e especialistas. ${ }^{26}$

\footnotetext{
${ }^{24}$ Ver em Arendt, 2011, p. 348.

${ }^{25}$ Para Arendt, nesta concepção de representação os eleitos se tornam "bons meninos de recados ou como especialistas contratados que, à maneira de advogados, dedicam-se a representar os interesses de seus clientes" (Arendt, 2011, p. 299). Dessa forma as instâncias parlamentares não são lugares de troca de opiniões e de deliberação em conjunto, mas onde se mede a força dos
} 
Neste contexto, tanto a economia quanto a questão social se tornaram as principais preocupações públicas de forma que a ação estatal visa a aumentar a produção e o consumo: o dinheiro público financia a economia e o consumo e, desse modo, sustenta a predominância da mentalidade do animal laborans. É no período histórico em que o Estado de bem-estar social está no auge que Arendt critica a ampliação do trabalho e a redução do espaço público nas democracias representativas. Ao estimular o consumo de massa por meio do financiamento da economia e de bens e serviços públicos, a esfera do trabalho foi ampliada e promovida. Ao colocar o bem-estar como finalidade da política e a administração burocrática como principal prática de governo, o espaço de debate e participação foi reduzido. ${ }^{27}$

A autora chama a atenção para o fato de que embora o Estado de bem-estar social tenha promovido direitos sociais, ele reduz a atividade política e também a dignidade humana. Na medida em que este tipo de Estado sustenta a mentalidade do animal laborans ele reduz os seres humanos a certas atividades e diminui o desenvolvimento de todas suas potencialidades, dentre elas a capacidade de agir em conjunto para definir os rumos dos mundo.

interesses particulares. No Estado de bem-estar social a esfera pública não é o lugar onde se forma interesse comuns, mas é o lugar de disputa de interesses particulares.

${ }^{26}$ Nas palavras de Arendt (2011, p. 340), "[...] e quem há de negar a que ponto a esfera pública em nossas sociedades de massa se encolheu e está sendo substituída por aquela 'administração das coisas' que Engels previa para uma sociedade sem classes?".

${ }^{27} \mathrm{Em}$ A Condição Humana Arendt narra o modo pelo qual o trabalho se tornou a principal atividade humana e quais as consequências disso para a fabricação e a ação. Já no prólogo a autora afirma: "A era moderna trouxe consigo uma glorificação teórica do trabalho, e resultou na transformação factual de toda a sociedade em uma sociedade trabalhadora" (Arendt, 2010a, p. 5). Sobre a relação entre sociedade de massa, burocracia e ampliação do trabalho, ver $\mathrm{p}$. 48-49. 


\section{Considerações finais}

Levando em conta o pensamento de Arendt, podemos notar que além de refletir sobre as formas de governo, é preciso pensar no sentido, finalidade e na concepção de governo e de política. Ainda, é preciso investigar qual espaço é dado à ação, e qual o papel da fabricação e da administração no governo. Em outras palavras, mais do que tratar da forma constitucional adotada - monarquia, democracia representativa, república -, é importante investigar também qual tipo de atividade o governo promove: a atividade política ou uma atividade externa à política. Ainda, é preciso levar em conta como se dá a divisão entre governantes e governados, qual o papel do povo, dos cidadãos, dos representantes e dos burocratas, qual atividade eles realizam e como.

Dentre todas reflexões que Arendt suscita, esta é uma das quais torna seu pensamento importante para nosso presente. Embora a autora tenha tratado do Estado de bem-estar social e não tenha assistido seu desmonte e a construção do Estado neoliberal, não se pode afirmar que as características do governo apontada por Arendt desapareceram completamente: a representação e a burocracia ainda marcam a concepção de governo. Persistem a importância da economia política na condução dos negócios públicos, a dificuldade de constituição de interesse público e o esforço de evitar a ação. Nesse contexto, é preciso interrogar que tipo de governo está se constituindo, de que maneira a representação, a fabricação e a administração se entrelaçam no neoliberalismo para que certos comportamentos, normas e modo de vida sejam promovidos. As categorias e análises de Arendt são importantes para que possamos pensar nestas questões. 
128

\section{Governo, ação, fabricação e trabalho}

\section{Referências}

ARENDT, H. Karl Marx and the tradition of Western political thougut. Social Research. Charlotte, v. 69, n. 2, 2002.

ARENDT, H. Entre o passado e o futuro. São Paulo: Perspectiva, 2005.

ARENDT, H. A condição humana. São Paulo: Forense Universitária, 2010a.

ARENDT, H. Sobre a violência. Rio de Janeiro: Civilização Brasileira, 2010b.

ARENDT, H. Sobre a revolução. São Paulo: Companhia das Letras, 2011.

Artigo recebido em 3/05/2018, aprovado em 19/05/2018 